UDC 620.9:622.012

N. Yu. SHEVYREVA ${ }^{1}$, Senior Lecturer, Candidate of Engineering Sciences, nshev90@yandex.ru

${ }^{1}$ Gubkin National University of Oil and Gas, Moscow, Russia

\title{
EFFECTS OF ACTIVE RECTIFIERS ON POWER QUALITY IN SUPPLY SYSTEMS IN MINERAL MINING INDUSTRY
}

\section{Introduction}

Recently the mining industry widely uses variable-frequency induction-motor drives (VFIMD). These drives enable energy saving, cost cutting and equipment reliability improvement. At the same time, the large-scale introduction of VFIMD in power supply systems of mines worsens the power supply performance: consumption of wattless power grows, and voltage waveform in electric mains is distorted because of higher harmonics generated by semiconductor converters. The increase in wattless power consumption results in higher losses in supply mains and in extra fluctuation of voltage in the mains. Voltage distortions deteriorate electric energy and induce undesirable effects on electrical customers and on power supply performance. As a result, electric power dissipation takes place in electrical facilities, life cycle of current-using equipment shortens because of extra ageing of electrical insulation, error of electric-type instruments grows, performance of automatics, teleautomatics, communication, etc. degrades [1, 2].

Until recently the power quality in the supply systems in the mineral mining industry, using electric drives with semiconductor converters has been maintained and improved thanks to LC-type filters composed of inductors and capacitors for compensating reactive power and filtering out higher harmonics [2].

One of the promising ways of improving power quality in operation of $A C$ VFIMD is addition of an active rectifier (AR) in a frequency converter (FC) [3-8]. FC with AR are an effective tool for the power quality improvement and energy saving in mining machines with VFIMD, and enjoy widening application therefore, for instance, in shovels [1, 4].

$A R$ is a rectifier with fully controlled semiconductor devices (e.g., triodes) which operate in the mode of pulse and width modulation (PWM). This allows the wanted power quality characteristics as power voltage excursion at the inlet of electrical equipment or the total harmonic factor value $\mathrm{KU}$, or the electric power factor equal to one.

At the same time, negligence of properties of the power supply and AR, or their interference and interaction can result in emergency situations. Thus, it is of the current concern to study the joint effects exerted by the supply system and VFIMD with AR on the power quality with regard to their properties and to develop recommendations on the selection of VFIMD with AR for specific mining machines and installations.

\section{Subject and task of research}

The joint effects of the power supply system and AR on the power quality was analyzed as a case-study of drilling equipment in oil and gas industry. The results are quite applicable to other mining machines, for instance, shovels. Figure 1 shows a standard electric circuit diagram of a drilling installation (DI) with VFIMD with local supply voltage of $6 \mathrm{kV}$. The DC link component of FC is AR $[9,10]$.

The electric circuit of a drilling installation includes a reducing transformer ( $T$ ), an active rectifier (AR), a capacitor $\left(C_{f}\right)$, self-commutated voltage inverters (SCVT) supplied by shared DC buses which also supply induction motors of main machinery of the drilling installation, which is in our case two mud pumps (MP 1 and MP 2), a rotor wheel (RW) and a winch (W). The motors have capacity of $1200 \mathrm{~kW}$, voltage of $690 \mathrm{~V}$ and rated speed of $1000 \mathrm{rpm}$.

Figure 1 presents the function chart of the automatic control system (ACS) of AR, which is based on vector ACS proposed in $[11,12]$.

The control system is implemented in the synchronous orthogonal coordinates $(x, y)$ oriented along the vector of the main voltage $U$, which enables controlling the active ix and idle iy components of the vector of the rectifier input current I [11].

Vector ACS contains single-loop ACS of the idle current $i_{y}$ and dual-loop ACS of the rectified voltage $U_{d}$, and the inner loop of the latter is the control loop of the active current $i_{x}$.

The signals of unbalance between the preset $\left(i_{x}^{\star}, i_{y}^{*}\right)$ and actual $\left(i_{x}, i_{y}\right)$ converted currents come to proportional integral 


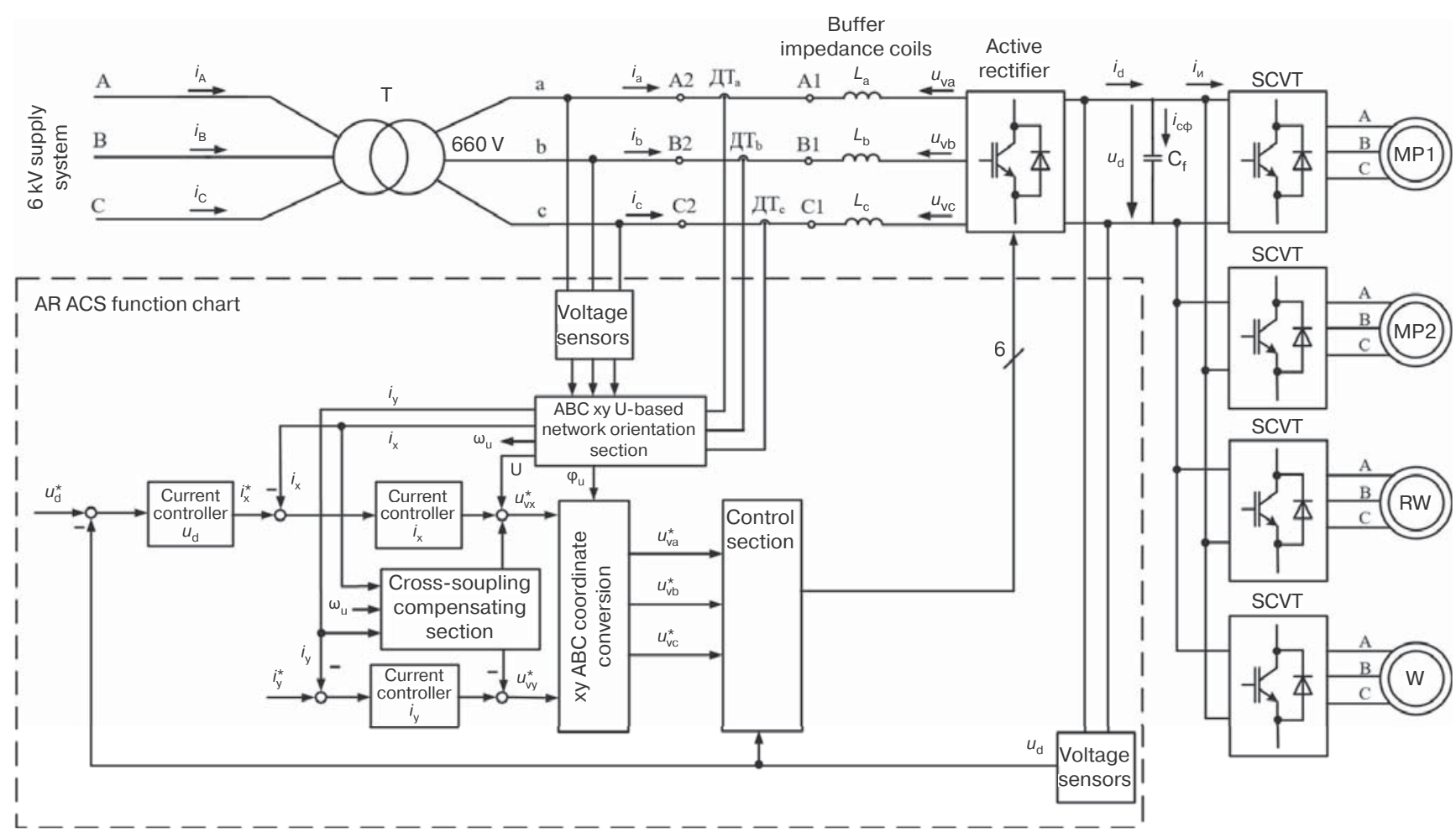

Fig. 1. Electric circuit diagram of DI with VFIMD and AR at local supply voltage of $6 \mathrm{kV}$

(PI) controllers. The outputs of the controllers, after addition of signals of compensative couplings, come to inlets of the coordinate converter of the control voltage vector $x y \rightarrow A B C$. After conversion of coordinates, the command variables $u_{\mathrm{va}}^{*}$ $u_{\mathrm{v} b}^{\star}$ and $u_{\mathrm{vc}}^{\star}$ are generated and sent to the control block of AR.

The rectifier capacity factor is adjusted by setting the idle input current $i_{y}^{*}$.

The command variables are $u_{\mathrm{v} x}^{*}$ and $u_{\mathrm{vy}}^{*}$, and the perturbation actions are the load current $i_{1}$ and the circuit voltage vector components $u_{x}$ and $u_{y}$. The controlled variables are the voltage $u_{d}$ at the output of AR and the line current vector components $i_{x}$ and $i_{y}[11,12]$. In the structure of AR, there are cross-couplings and the internal feedback by the rectified voltage $u_{d}[11,12]$.

For synthesizing vector ACS of AR, compensation of cross-couplings, internal feedback by the rectified voltage $u_{d}$ and perturbation by the line voltage $U$ is performed. As a result, vector ACS of AR is synthesized based on subordinate adjustment of coordinates [11, 12].

The transfer functions of $i_{y}$ and $i_{x}$ current controllers and rectified voltage $u_{d}$ controllers are performed by PI controllers [11].

The analysis of factors of the current controller transfer functions shows that they depend on inductive and active resistances of the power supply, which should be taken into account in determination of factors of the transfer functions. In the meanwhile, during operation of VFIMD, the inductive and active resistances of the power supply vary within wide ranges for different reasons. The control system should be set with regard to this circumstance; otherwise, various fluctuations can arise during transient and steady-state processes and result in power deterioration and in breakdown of electrical equipment, including motors.

A filter at the inlet of $A R[1,5]$ can be connected on the DC side of AR to the points A1, B1, C1 or A2, B2, C2 (Fig. 1). The influence of the filter was disregarded in the synthesis of the controller. Similarly, this can result in various fluctuations and emergencies.

The analysis of the effects generated by the power supply and filter of AR on the quality of the transient and steady-state processes can make it possible to develop recommendations on the synthesis of vector ACS of AR, which can enable elimination of various fluctuations and, as a consequence, avoid power deterioration.

The research used a computer model $[9,10]$. The model consisted of an electric circuit of a drilling installation with VFIMD and AR at the local power line of $6 \mathrm{kV}$ and a function chart of vector ACS of AR (See fig. 1). Modeling was implemented in MatLab with Simulink SimPower Systems.

\section{Results}

The tests were carried out with feed lines 1 and $7 \mathrm{~km}$ long, without and with AR filter in the form of a three-phase spiderlike circuit of capacitors.

Using the developed model, we determined the supply voltage fluctuation $(\delta U)$, the total harmonic factor $(K U)$ and the first harmonic power factor $(\cos \varphi)$ at $6 \mathrm{kV}$ inlet of the converter transformer.

We tested two variants of AR filter inclusion: variant 1 - the filter is included between the current sensors and AR (points A1, $B 1, C 1)$; variant 2 - the filter is included between the converter transformer and the current sensors of AR (point A2, B2, C2).

The current controllers were set for the operation at the maximal length of the feed line, i.e. $7 \mathrm{~km}$, and remained unaltered at the changed length of the feed line in the tests carried out without regard to the feed line length. In the tests with regard to the feed line length, the current controllers were reset when the length of the feed line was changed. 
Table 1. Test data on power quality in steady-state mode of operation with AR current controllers set without regard to feed line length change (filter inclusion variant 1 )

\begin{tabular}{|l|c|c|c|}
\hline \multicolumn{1}{|c|}{ Feed line length } & $\cos \varphi$ & $\delta U, \%$ & $K_{U}, \%$ \\
\hline $1 \mathrm{~km}$ (AR filter is disactivated) & 0.97 & 1 & 16.5 \\
\hline $1 \mathrm{~km}$ (AR filter is actuated) & 0.95 & -15 & 300 \\
\hline $7 \mathrm{~km}$ (AR filter is disactivated) & 0.98 & -9 & 25 \\
\hline $7 \mathrm{~km}$ (AR filter is actuated) & 0.98 & -9 & 3.5 \\
\hline
\end{tabular}

Thus added, the testing scenarios are as follows:

- the AR current controllers are set for the operation with and without regard to the feed line length change and without AR filter;

- the AR current controllers are set for the operation with and without regard to the feed line length change and with AR filter included between the current sensors and AR (variant 1) and between the converter transformer and AR current sensors (variant 2).

Table 1 gives the test data on power quality with the current controllers set without regard to the feed line change. AR filter is between the current sensors and AR (variant 1). It is seen in Table 1 that the power factor is independent of the feed line length and AR filter presence, and keeps at the level of $0.95-0.98$.

The voltage fluctuation at the feed line length of $7 \mathrm{~km}$ is never higher than the guideline value of minus $10 \%$ with and without the filter [13].

The total harmonic factor $\left(K_{U}\right)$ at the feed line length of 7 $\mathrm{km}$ and without the filter makes $25 \%$. As the filter is actuated, $\mathrm{KU}$ drops to $3.5 \%$, which agrees with the guideline value of $5 \%$ [13].

With the feed line $1 \mathrm{~km}$ long and without AR filter, the voltage fluctuation is almost absent and $K_{U}$ is $16.5 \%$.

However, when the feed line length is $1 \mathrm{~km}$ and the filter is actuated (variant 1), the voltage fluctuation increases to minus $15 \%$ and $K_{U}$ jumps to $300 \%$.

Accordingly, the active filter of AR between the rectifier and the current sensors in case of the shorter feed line induces current resonances in the power mains.

To prove the afore-said, Fig. 2 shows the composition of harmonics in the mains, and Fig. $\mathbf{3}$ describes the transient processes in ignition and braking of the motor. It is seen in Fig. 2 that the current resonance occurs on the 17th harmonic, which results in essential fluctuation of supply voltage. The oscillograms of the speed and moment in Fig. 3 are reflective of the drive malfunction in this case. The drive moment oscillations can lead to breakdown of the motor.

The test data on the power quality in the steady-state operation with setting of AR current controller with regard to the feed line length changes with the actuated filter in variant 1 are compiled in Table 2. It is evident that the power factor is independent of the feed line length and AR filter presence, and keeps at the level of 0.96-0.98.

The supply voltage fluctuations with the feed line length of $7 \mathrm{~km}$ are never higher than the value of minus $10 \%$ both with and without the filter.

The total harmonic factor (KU) at the feed line of $7 \mathrm{~km}$ without the filter reaches $25 \%$. With the filter actuated, KU drops to $2.7 \%$, which is below the guideline value of $5 \%$.

When the feed line is $1 \mathrm{~km}$ long, both with and without AR

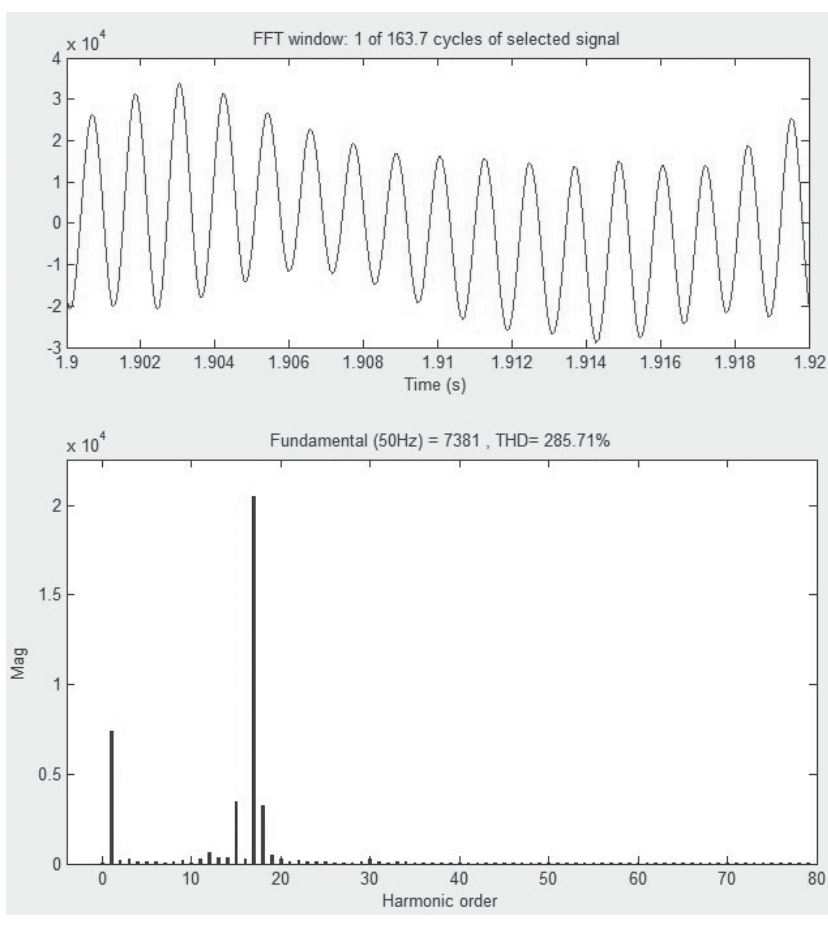

Fig. 2. Voltage harmonics in the mains without regard to supply system properties with set current controllers of actuated AR filter (variant 1)

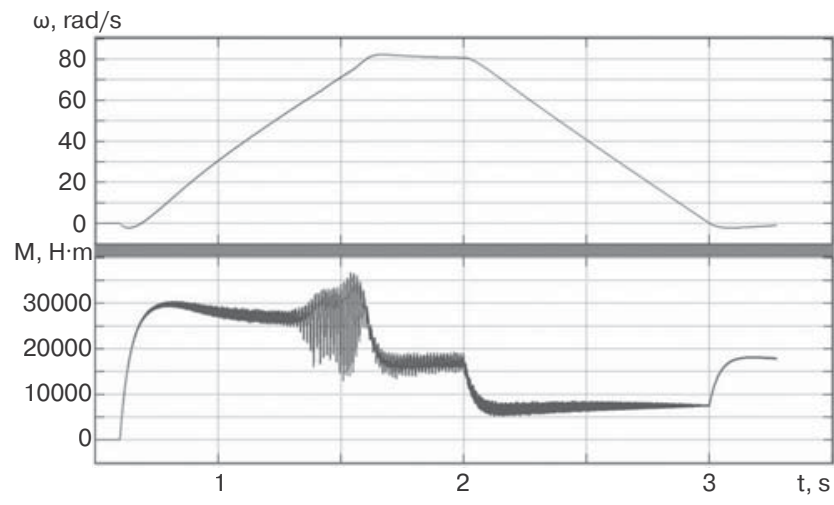

Fig. 3. Transient processes in electric drive without regard to supply system properties with set current controllers of actuated AR filter (variant 1)

filter, there are no voltage fluctuations. The value of $\mathrm{KU}$ without the filter is $16 \%$. When the filter is actuated, $\mathrm{KU}$ drops to $2.3 \%$, which is lower than guideline value $5 \%$.

Consequently, when the current controllers are set with regard to the length of the fed line, actuation of AR filter by variant 1 at the short feed line results in no current resonances in the power supply system. This is proved by the plots in Figs. 4 and 5 .

Figure 4 shows the harmonics and almost sinusoidal waveform of the voltage.

Figure 5 presents the transient processes in the electric drive. The oscillograms of the speed and moment show that the drive moment oscillations are absent.

The analysis of the test data obtained with AR filter actuated by variant 1 shows that the presence of the filter in case 
Table 2. Test data on power quality in steady-state mode of operation with AR current controllers set with regard to feed line length change (filter inclusion variant 1)

\begin{tabular}{|l|c|c|c|}
\hline \multicolumn{1}{|c|}{ Feed line length } & $\cos \varphi$ & $\delta U, \%$ & $K_{U}, \%$ \\
\hline $1 \mathrm{~km}$ (AR filter is disactivated) & 0.98 & 1 & 16 \\
\hline $1 \mathrm{~km}$ (AR filter is actuated) & 0.96 & 1 & 2.3 \\
\hline $7 \mathrm{~km}$ (AR filter is disactivated) & 0.98 & -10 & 25 \\
\hline $7 \mathrm{~km}$ (AR filter is actuated) & 0.98 & -10 & 2.7 \\
\hline
\end{tabular}

Table 3. Test data on power quality in steady-state operation of AR current controllers set without regard to length of feed line (filter actuation variant 2)

\begin{tabular}{|l|c|c|c|}
\hline \multicolumn{1}{|c|}{ Feed line length } & cos & $U, \%$ & $K_{U}, \%$ \\
\hline $1 \mathrm{~km}$ (AR filter is disactivated) & 0.97 & 1 & 16 \\
\hline $1 \mathrm{~km}$ (AR filter is actuated) & 0.98 & 1.5 & 2.2 \\
\hline $7 \mathrm{~km}$ (AR filter is disactivated) & 0.98 & -9 & 25 \\
\hline $7 \mathrm{~km}$ (AR filter is actuated) & 0.99 & -7 & 2.7 \\
\hline
\end{tabular}

Table 4. Test data on power quality in steady-state operation of AR current controllers set with regard to length of feed line (filter actuation variant 2)

\begin{tabular}{|l|c|c|c|}
\hline \multicolumn{1}{|c|}{ Feed line length } & $\cos$ & $U, \%$ & $K_{U}, \%$ \\
\hline $1 \mathrm{~km}$ (AR filter is disactivated) & 0.98 & 1 & 16 \\
\hline $1 \mathrm{~km}$ (AR filter is actuated) & 0.98 & 2 & 2.2 \\
\hline $7 \mathrm{~km}$ (AR filter is disactivated) & 0.98 & -10 & 25 \\
\hline $7 \mathrm{~km}$ (AR filter is actuated) & 0.99 & -10 & 2.7 \\
\hline
\end{tabular}

of erroneous setting of AR current controllers, without regard to the feed line length, results in the current resonances in the supply system, in the essential distortion of the sinusoidal waveform of the voltage and, as a consequence, in breakdown of the electrics, including the drive.

Inclusion variant 1 of AR filter, with AR current controllers set with regard to the feed line length results in no current resonances in the supply system, in no voltage waveform sinusoid distortion or accidents. In this case, the filter actuation allows an essential reduction in the factor $K_{U}$, which is under the guideline value of $5 \%$. When the filter is absent, the total harmonic factor $K_{U}$ exceeds the rated standard.

Tables $\mathbf{3}$ and $\mathbf{4}$ give the test data on the power quality in the steady-state mode of operation with setting of AR current controllers without and with regard to the feed line length, respectively.

The comparison of the test data in Tables 3 and 4 allows drawing some conclusions below.

The power factor is independent of the feed line length and presence of AR filter, and remains at the level of 0.97-0.99.

The supply voltage fluctuations at the tested feed line lengths of 1 and $7 \mathrm{~km}$ both with and without the filter are never higher than the rated value of minus $10 \%$.

The total harmonic factor $\left(K_{U}\right)$ at the feed line length of 7 $\mathrm{km}$ and without the filter reaches $25 \%$. With the actuated filter, $K_{U}$ drops to $2.7 \%$, which is below the guideline value of $5 \%$.

With the feed line $1 \mathrm{~km}$ long and without the filter, $K_{U}$ is $16 \%$. When the filter is actuated, $K_{U}$ goes down to $2.2 \%$, which is under the guideline value of $5 \%$.

The test data analysis shows that in the studied variants, AR filter actuation by variant 1 , as against variant 2 , results in no
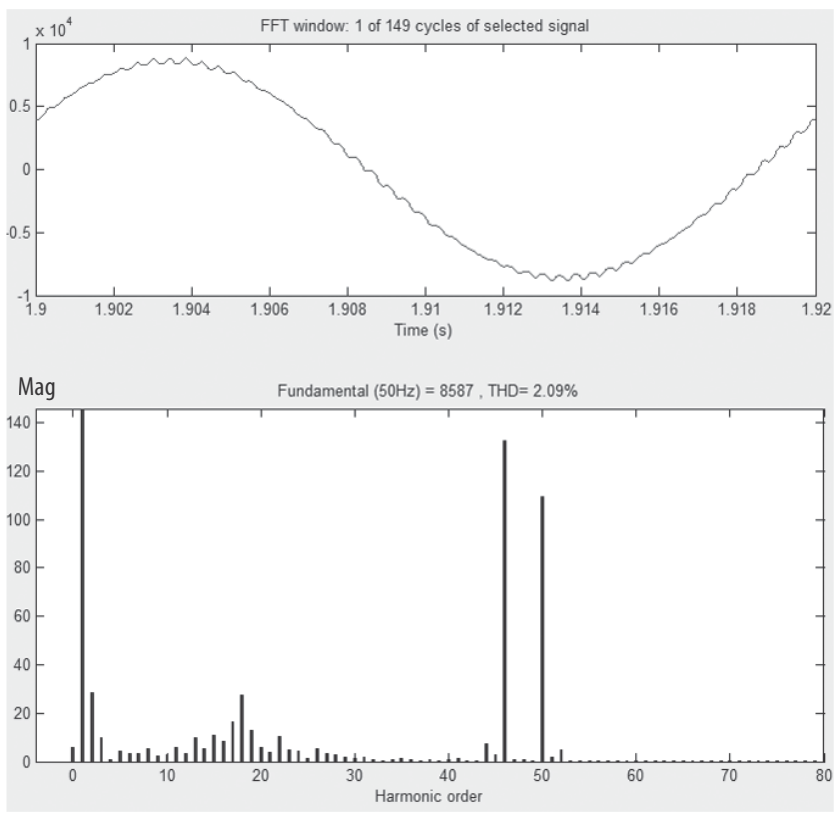

Fig. 4. Voltage harmonics in supply system with regard to its properties with set current controllers of actuated AR filter (variant 1)

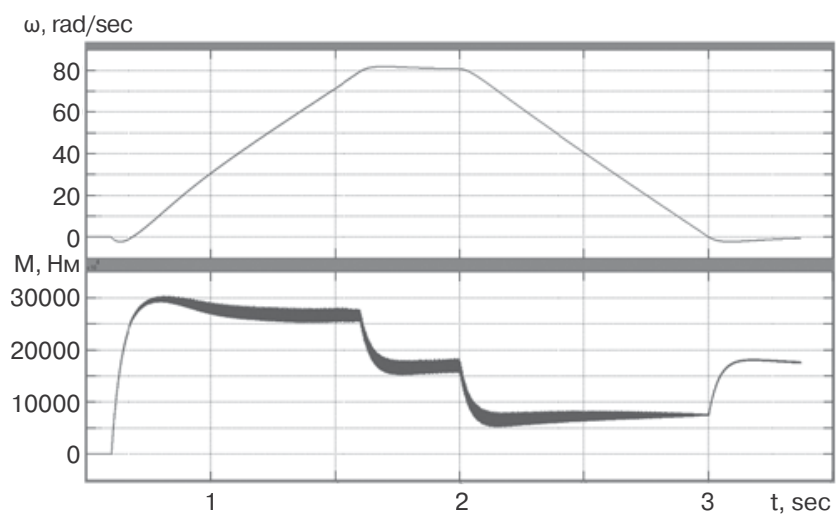

Fig. 5. Transient processes in electric drive with regard to supply system properties with set current controllers of actuated AR filter (variant 1)

current resonances in the power supply system when AR current controllers are set without regard to the feed line length.

\section{Conclusions}

The parameters of current controller of an active rectifier depend on the parameters of the power supply system and on the presence of AR filter, which should be taken into account when setting the current controllers. Otherwise, various fluctuations can arise and the power quality can deteriorate, which can result in breakdown of electrical equipment, including drives.

Setting of the current controllers essentially depends on the place of inclusion of AR filter in the circuit. In case of AR filter inclusion by variant 1 , it is required to set AR current controllers with regard to feed line length. Otherwise, the current 
resonances can arise in the supply system, especially when the feed line is short.

In order to have the guideline value of the total harmonic factor, it is necessary to use AR filter. The total harmonic factor, given fulfilled recommendations on setting of AR current controllers with regard to the joint effects of the power supply system and AR filter on the quality of the transient and steadystate processes, is not higher than the guideline value of $5 \%$.

\section{References}

1. Shevyrev Yu. V., Shevyreva N. Yu. Improvement of voltage waveform in power supply systems with dynamic rectifier in mineral mining and processing industry. Gornyi Zhurnal. 2019. No. 1. pp. 66-69. DOI: 10.17580/gzh.2019.01.14

2. Abramov B. I., Parfenov B. M., Shevyrev Yu. V. Choice methods of the parameters of filter compensating stepped type devices for thyristor electric drives. Elektrotekhnika. 2001. No. 1. pp. 38-42

3. Maklakov A. S., Radionov A. A. Influence of afe rectifier with different types of PWM on supply power. Russian Internet Journal of Industrial Engineering. 2013. No. 2. pp. 40-47.

4. Munoz-Guijosa J. M., Kryltcov S. B., Solovev S. V. Application of an active rectifier used to mitigate currents distortion in 6-10 kV distribution grids. Journal of Mining Institute. 2019. Vol. 236. pp. 229-238.

5. Rajendra Aparnathi, Ved Vyas Diwedi. Study of the LCL Filter for Three Phase inverter in higher stability for the Active damping Method using Genetic Algorithm Base. International
Journal of Advancements in Technology. 2013. Vol. 4, No. 1. pp. 36-49.

6. Naziya S., T. M. Thamizh Thentral. Vector Control of Active Front-End Rectifier for Electric Motors under Unbalanced Condition. International Journal of Science and Research. 2015. No. 4. pp. 1375-1379.

7. Singh B., Singh N. B., Chandra A., Al-Haddad K., Pandey A., Kothari D. P. A Review of Three-Phase Improved Power Quality AC-DC Converters. IEEE Transactions on Industrial Electronics. 2004. No. 3. pp. 641-660.

8. Aswathi G., Nalini S., Kumar R. S. Simulation of Active Front End Converter Based VFD for Induction Motors. International Journal of Scientific and Engineering Research. 2013. No. 6. pp. 322-327.

9. Shevyreva N. Yu. Regularities of influence variable frequency drive with an active rectifier on power quality. Vesti vysshikh uchebnykh zavedeniy Chernozemya. 2015. No. 4. pp. 26-35.

10. Shevyreva N. Yu. Simulation of frequency controlled electric drive with active front end. Glavnyi energetik. 2015. No. 8. pp. 69-74.

11. Vinogradov A. B. Vector control of AC drives. Ivanovo : IGEU, 2008. 298 p.

12. Shreiner R. T. Mathematical modeling of AC drives with semiconductor frequency converters. Yekaterinburg : UrO RAN, 2000. $654 \mathrm{p}$.

13. GOST 32144-2013. Electric energy. Electromagnetic compatibility of technical equipment. Power quality limits in the public power supply systems. Moscow : Standartinform, 2014. 20 p. Em 